\title{
REVISTA INDEXADA EN SCIELO
}

\author{
INDEXED JOURNAL IN SCIELO \\ Jhony A. De La Cruz-Vargas s, $2, \mathrm{~b}, \mathrm{c}, \mathrm{c}^{2}$
}

Hoy tenemos el honor y la alegría de compartir con la comunidad científica y universitaria que la "Revista de la Facultad de Medicina Humana de la Universidad Ricardo Palma" se encuentra indexada en múltiples bases nacionales e internacionales, la mas reciente en Scielo.

Todo esto ha sido posible gracias a todo el apoyo recibido de las autoridades de la Universidad, y especialmente de nuestro Rector el Dr. Iván Rodríguez Chávez, quien en todo momento nos brindó su motivación, respaldo, apoyo y nos ha inspirado con su ejemplo y trabajo.

El proceso de indización de una revista científica es laborioso, requiere tiempo y la confluencia de recursos humanos capacitados, trabajo en equipo, identidad con la universidad, voluntad política institucional para disponer de los elementos técnicos y administrativos necesarios para alcanzar los objetivos, pero especialmente un equipo editor investigador, con liderazgo y capacidad de gestión.

Indexar una revista implica dejar de ser literatura gris y pasar a formar parte de bases y repositorios internacionales que exigen cumplir con una serie de rigurosos estándares técnicos y de calidad de contenido original, revisión por pares, así como cumplir con la frecuencia y periodicidad de las publicaciones. En el Perú y en Latinoamérica, son pocas las revistas indexadas, por lo que trabajar en este campo significa contribuir a la difusión de la producción científica de calidad y aumentar la visibilidad y posicionamiento de nuestras instituciones.

Con enorme satisfacción, hoy podemos decir: hemos alcanzado indexar la Revista de la Facultad de Medicina Humana de la Universidad Ricardo Palma en Scielo. El camino ha sido largo, pero lleno de desafíos y lecciones para todo el equipo de trabajo de la revista.

La Revista de la Facultad de Medicina Humana de la Universidad Ricardo Palma, fue fundada por el Dr. Manuel Huamán Guerrero e inicio su primera publicación en el año 1999. Se gano un lugar como la publicación de Medicina Humana y recibió el apoyo de docentes e investigadores de la Facultad y de los Hospitales.

En el año 2016, recibí la invitación del Dr. Huamán para colaborar con la edición de la revista, y en el año 2017 como Coeditor planteamos una reingeniería de la revista. Fuimos la primera revista de la Universidad Ricardo Palma en obtener el DOI (Identificador Digital Objetivo), a través de la gestión del Instituto de Investigación en Ciencias Biomédicas de la Universidad Ricardo Palma, convirtiéndose en membership de CROSSREF.

Con la Facultad de Medicina Humana nos propusimos y obtuvimos las siguientes indexaciones en el 2017-2018:

1. LATINDEX CATÁLOGO 2.0

2. CROSSREF

3. REDIB

4. ACADEMICKEYS

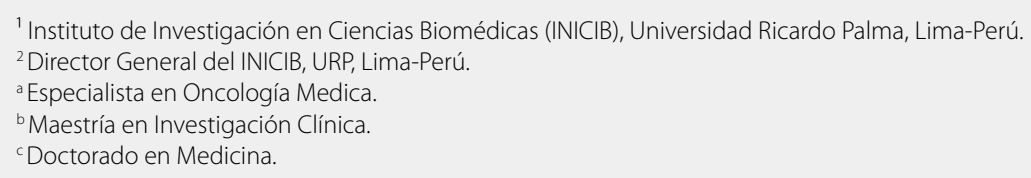




\section{GOOGLE SCHOLAR}

En el año 2019 alcanzamos indexar la revista en:

6. DOAJ

7. ALICIA-CONCYTEC

8. SCIELO.

\section{LILACS OMS / OPS}

Es importante llegar a la cima de la montaña, pero resulta aun mas importante mantenerse en ella Esto implica nuevos desafíos, capacidad creativa y de innovación, mejora de procesos y exigencias diferentes para marcar los artículos para Scielo, consolidar la calidad de las publicaciones originales, expandir la edición bilingüe full tex, optimizar la gestión y uso de las plataformas, así como aumentar el impacto y aplicación de la revista. Ya estamos trabajando para pronto estar en la plataforma: DIGITAL COMMONS de Elsevier, así como para ingresar a la base de la OMS/OPS LILACS.

Nuestro próximo reto es alcanzar un desafío mayor para el 2021, no solo seguir publicando artículos en SCOPUS, sino ser parte de SCOPUS, indexando la Revista de la Facultad de Medicina Humana de la Universidad Ricardo Palma en esta prestigiosa base internacional. Para ello estaremos presentando a la Universidad para su aprobación el plan estratégico de indización de la revista en SCOPUS.

Dedicamos este logro a nuestros maestros, a todo el equipo de trabajo de la revista y a la memoria de los que iniciaron el camino en la Facultad de Medicina Humana, que hoy nos toca continuar y honrar.
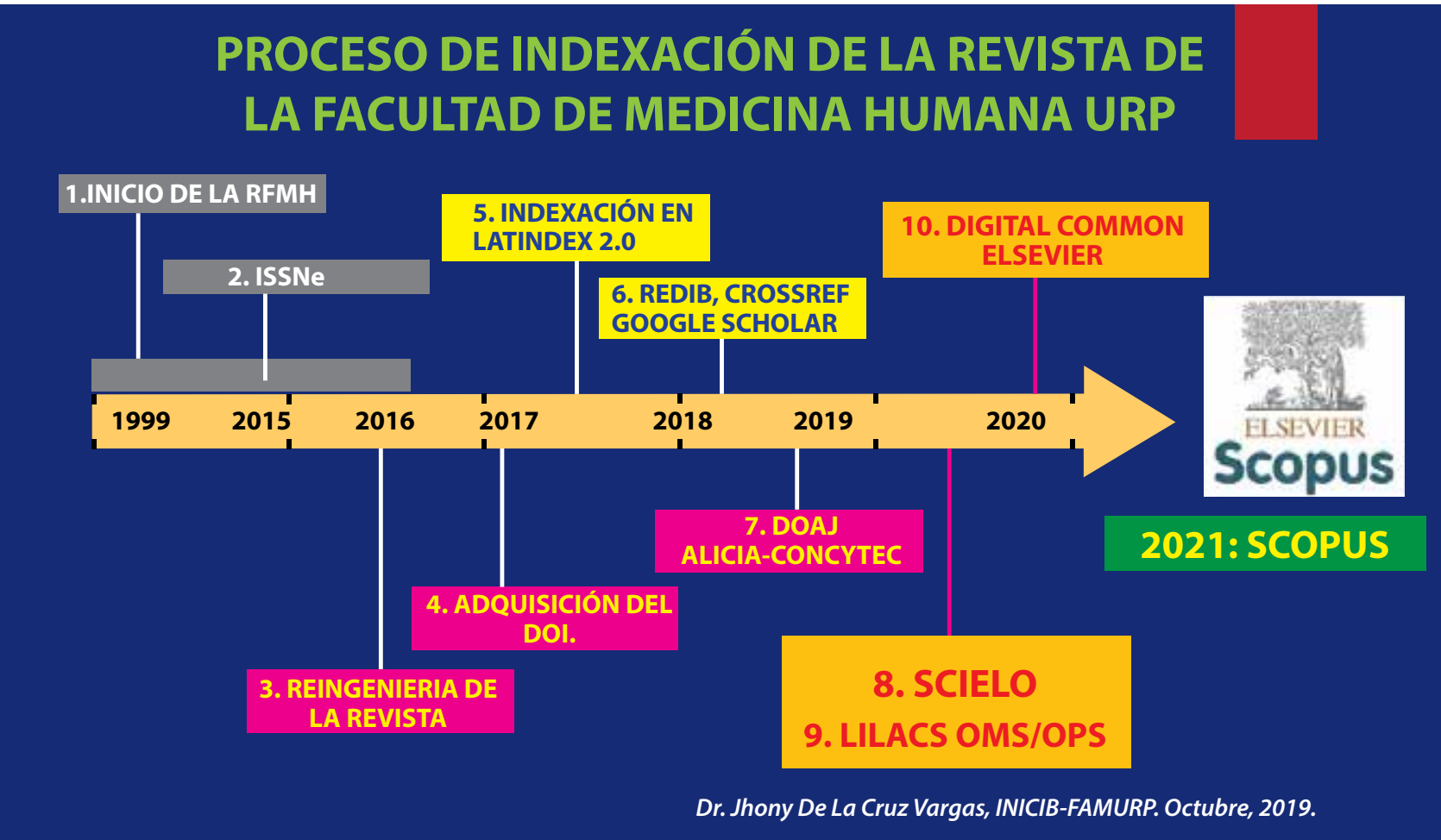

Figura 1. Proceso de indexación.

\section{Correspondencia: Jhony A. De La Cruz Vargas}

Dirección: INICIB, Facultad de Medicina Humana, Edificio I-208. 2do piso. Avenida Benavides 5440, Surco, Lima-Perú. Teléfono: 708-0000 / Anexo: 6016

Correo:jhony.delacruz@urp.edu.pe 